Article

\title{
How to Increase Customer Satisfaction by Beautifying Sports Facilities? What is the Key Role of Service Quality?
}

\author{
Mohammadbagher Forghani Ozrudi \\ Department of Physical Education, Education Office, Babol, Iran \\ * Correspondence: mohammadbagher.forghani@gmail.com
}

How to cite this paper: Ozrudi, M. F. (2022). How to Increase Customer Satisfaction by Beautifying Sports Facilities? What is the Key Role of Service Quality?. Universal Journal of Sport Sciences, 1(1), 28-32. Retrieved from

https://www.scipublications.com/jou rnal/index.php/ujss/article/view/226

Received: January 1, 2022

Accepted: February 24, 2022

Published: February 25, 2022

Copyright: $\odot 2022$ by the authors. Submitted for possible open access publication under the terms and conditions of the Creative Commons Attribution (CC BY) license (http://creativecommons.org/licenses /by/4.0/).

\begin{abstract}
The purpose of this study was to investigate the key role of service quality and beauty of sports facilities in increasing customer satisfaction. The research method is descriptive and correlational research. The statistical population of the study was 154188 organized athletes covered by sports insurance (103890 men, 50298 women) who were working in sports halls of Mazandaran province and according to Morgan table, 384 athletes were randomly selected by cluster Were. Aesthetic questionnaire, service quality and customer satisfaction were used to collect information. Data analysis was performed using Pearson test and structural equation modeling by SPSS24 and Amos structure analysis software. According to the research results, the indirect effect of aesthetics of sports venues on increasing customer satisfaction through service quality is significant. Managers can take effective steps to increase their presence and increase the income of gyms by using quality improvement strategies and customer satisfaction.
\end{abstract}

Keywords: Beauty, Customer, Sports Facilities, Service Quality, Satisfaction

\section{Introduction}

Today, in the modern world, one of the factors that attracted the attention of a city view and are a factor in terms of urban development, is the creation and construction of luxurious, attractive and advanced sport facilities [1]. If these spaces are modern, efficient and up to date, they represent the image of a city[2] .

All developed countries are planning in the field of efficient sport facilities [3]. Countries are trying to develop their cities much better and for this, they do very large investment for the construction of the places [4]. With regard to limited land and resources, it is necessary to pay special attention to the beauty and being efficient in terms of lower power consumption during designing sporting venues, As well as the date and it's charming [3]. Impressive means being luxury and ultimately beauty as any kind of relationship cause Prestige. Generally, an impressive space is combined with modern and expensive technology and is related to society's upper-class life [2]. Today, the beautiful appearance of a building can be a factor that encourages the viewer to enter it [4].

In the third millennium Exercise is considered as a principle for all societies, and governments always are planning for their citizens, in relation to the sport and making sport facilities [5]. Also, in their plans they don't consider only the citizens, but also, they benefit from impressive sporting venues as a tourist attraction [3]. With creating impressive sport facilities, they also create jobs and they are successful in attracting investment, they provide sport services for the people either [2]. Today, Sports tourism is one of the most thriving in tourism industry and to create that, it is necessary to have impressive and modern sport facilities such as spa centers and modern sport clubs and modern hotel adjacent to the mineral water [6]. In fact, today, the culture of fun and happy sports is combined with the culture of trips and [7], it needs to have beautiful and 
functional sport facilities [2]. Today our country is far lower than in the developed countries in the field of construction of modern sports facilities [8]. The beauty and charm of sports facilities and sports venues is an important factor for architects and designers, because the number of beneficiaries of these places are much higher than residential [9].

Countries that make their own luxurious Sport facilities themselves, prevents from exiting money of their country and with this, they help their economy [6]. In developed countries in terms of architecture, today, according to the cost for construction of buildings, they pay attention to another important consideration which is the physical beauty or appearance, and it places an important role in the public image of the society [10]. While we do not use modern science of sports architecture to build sport facilities [11]. Sports and supporting it, give identity role to the inhabitants of one area and what it needs are sport facilities, and as an infrastructure, the more beauty, the more prestige will create $[12,13]$. Given these facts, we refer briefly to the titles of the problems in our country. The lack of sport facilities with beautiful tourist attractions and as a result, lower contributions of sports tourists [14]. Not using the science of modern impressive sport facilities construction [8]. Removal of significant amounts of foreign currency from the country because of the lack of modern impressive sport facilities [15]. Sport facilities are not beautiful [16].

All these problems are the reasons for choosing this subject by researchers and having experience to build sport facilities and having interest in this matter would help. Researches have been done in these backgrounds. For example, Haghgoo \& Vediyeh Mulla Salehi achieved results in terms of places in the best cities, such as the importance of color in the view of the city and the lighting of the world's top cities appearance. The research aims to highlight significant impressive sport areas of sport and specify its role in view of the city [17]. Nopembri, in research, with the title of development of sport facilities and its relation to tourist attractions sporting venues of entertainment for tourists, came to the conclusion that in Southeast Asian countries like Indonesia, Thailand, Malaysia, Maldives the construction of multi-purpose sports sites has been in power for job creation and tourism and earn more money. In addition to the hotels and clubs, these countries as tourist destinations, design sports facilities very impressive[6] .

By doing this research, the Researcher wants to consider beneficiaries view to the beauty and charm of the variable sport facilities, to see if there is any significant correlation, in order to attract the idea of policy makers and urban planners in terms of building sport facilities. Among these, to what extent the quality of service can return the customers to re-use this sporting venues. So, the important question that researchers are trying to find the answer is, to what extent the construction of sport facilities at attractive rates affect customer's satisfaction? And does the construction of advanced and impressive sport facilities affect in improving the appearance of the city?

\section{Materials and Methods}

According to the topic, this research is a cross-correlation research and is practical in terms of purpose and was conducted in the field. The population of the study, the number of 154,188 organized athletes' sport's insurance coverage (103890 men, 50298 women), 384 athletes were selected randomly according to Morgan's table. Data for this study consists of four questionnaires. The demographic questionnaire consisted of questions such as gender, marital status, age, education level, and the frequency of using sports sites. The aesthetic questionnaire (Koshesh et al, 2015) [4], has two parts, and each question has 5 options for response. In the first part, the subject's ideas about aesthetic of sport facilities are evaluated (19 questions) and in the second part economically using attractive sporting venues for customers is evaluated (8 questions). Standardized questionnaire of assessing the quality of sports centers (Liu et al, 2012) [18], was used for data collection after adjustment and implementation gym environment and cultural conditions. Also, the 
modified customer satisfaction questionnaire (Ghasemzadeh et al, 2014) [19], was used to measure customer satisfaction from sport facilities. Statistical techniques Kolmogorov Smirnov test, Pearson correlation was used to test the hypothesis of a significant level of $\mathrm{p}<0 / 05$. The structural equation modeling and mediating regression analysis was used to determine the role of mediator. Analyses were analyzed using software SPSS22 torque structure analysis software (AMOS).

\section{Results}

The Participants average age was $19-29$ years with a $26.56 \% .48 .43 \%$ female, $44.79 \%$ single, $22.92 \%$ had master's degree or higher and $48.69 \%$ use gym two to three times a week. The $13.96 \%$ of the participants use Sports venues $\neg$ in order to become healthy. The description of variable external view and attractive $4.27 \pm 0.55$ and variable points of the facade with an attractive interior with $4.19 \pm 0.68$, variable cost $4.39 \pm 0.61$, and variable customer satisfaction with $3.72 \pm 0.54$ points respectively.

Table 1. Results of research hypotheses

\begin{tabular}{cccc}
\hline Variables & N & $\begin{array}{c}\text { correlation } \\
\text { coefficient }\end{array}$ & $\begin{array}{c}\text { Sig. } \\
\text { (2-tailed) }\end{array}$ \\
\hline Beauty of sports facilities * Improving the city view & 384 & 0.392 & 0.001 \\
Exterior view of sports facilities * Customer satisfaction & 384 & 0.373 & 0.001 \\
Interior view of sports facilities * Customer satisfaction & 384 & 0.748 & 0.001 \\
\hline Build beautiful * attractive sports facilities with economic justification & 384 & 0.667 & 0.001 \\
\hline
\end{tabular}

There is a relation Between Aesthetic Attractive sports facilities and the view of the city $(\mathrm{p}=0.001, \mathrm{r}=0.39)$. There is a relation between the external facade of the sports facilities and the amount of the customer's satisfaction ( $\mathrm{p}=0.001, \mathrm{r}=0.37)$. There is a relation between the inside view of the sports facilities and the amount of the customer's satisfaction $(p=0.001, r=0.75)$. There is also a relation between the construction of the attractive sports facilities and respect to the admission of economic growth $(\mathrm{p}=0.001, \mathrm{r}=0.67)$. The quality of the services as the relationship between sports facilities and customer's satisfaction is impressive.

Table 2. Results of structural equation modeling for conceptual and theoretical models

\begin{tabular}{|c|c|c|c|c|c|c|c|c|c|c|c|}
\hline $\begin{array}{c}\text { Template } \\
\text { routes }\end{array}$ & B & SE & $\beta$ & $\mathbf{R}^{2}$ & $\mathbf{X}^{2}$ & 田 & 疋 & 罙 & 思 & $\frac{d}{n}$ & 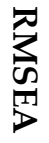 \\
\hline $\begin{array}{l}\text { Quality of } \\
\text { service and } \\
\text { aesthetic }\end{array}$ & 0.362 & 0.05 & 2.524 & 0.47 & & & & & & & \\
\hline $\begin{array}{l}\text { Quality of } \\
\text { service and } \\
\text { customer's } \\
\text { satisfaction }\end{array}$ & 0.163 & 0.02 & 0.641 & 0.3 & 0.158 & 1 & 0.976 & 0.996 & 1 & 11.23 & 0 \\
\hline
\end{tabular}

As you see on the table you can see the first row the beta coefficient, is accounted a measure of aesthetic sport facilities with $2.524,47 \%$ of the variance in the quality of services. In the second row of the table shows the effectiveness of beta coefficient measures $0.641,30 \%$ the percentage of variance accounted customers. Index $\neg$ By fitting provided in 
the seventh to thirteenth column of Table 2 all showed good fitness model shown in Figure 1 with data of research. In Figure 1 research model based on standard coefficients and explained variance of each variable interface (Quality of Service) and criteria (customer satisfaction) are given.

$(0.47)$

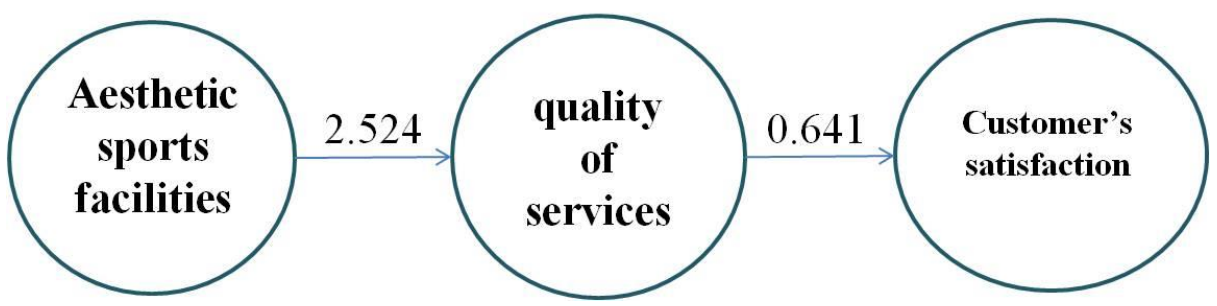

Figure 1. Standardized coefficients and explained variance service quality and customer satisfaction

According to calculations, the effect of non-standard method of direct aesthetic sport facilities on customer satisfaction is significant through quality of service.

\section{Discussion}

The main purpose of the research was to study the relationship between the facade with attractive sports facilities and the quality of service and the amount of the customer's satisfaction. The results of the physical theory of the effect of the transition to a service as of the Association of the relationship between these places following the exercise of such knowledge and customer's satisfaction showed that the quality of services, as a mediator, impact on both factors and increase customer's satisfaction. The results have been consistent with the results of Bahlakeh et al (2009), Goharrostami (2009), Hamzehpour (2012), Amirnezhad et al (2013), Hasibi et al (2014), Hosseini et al (2014). Forghani Ozrudi et al (2016), Ghasemi \& Forghani Ozrudi (2021) [1, 20-25]. This means that if the managers of sports centers focus on the quality of service and consider its various aspects, in addition to aesthetic sport facilities, they can increase customer's satisfaction and to return them again, or in other words, increasing their loyalty. Therefore, it may be said that Managers focus on strategy quality improvement and customer satisfaction, can be an effective step in the direction of more presence and increase their income.

Sports hall management approach should be Coherent, recruitment and retention and help customers interact with customers, manage and coordinate through customer satisfaction surveys. On the other hand, seeking for Customer's complaints is an important part of the definition of the desired services. Seeking to customer's complaints and demands as the opportunity to communicate with customers, should be taken into consideration by club's managers that increase mutual trust between the customer and the club. Also, another one of the possibilities may shorten the time period between the findings of this call customer service at the club is good that can be created that makes the difference in the satisfaction of its components. With proper notification of their service, clubs can increase the quality of services. The use of qualified staff with public relations and attention to the syntax of the service provider and has enough information about how to deal with the customer causes increase customer's satisfaction.

\section{Conclusions}

On the other hand, lack of proper notification not being a clear and positive image of the governmental clubs is also can be due to lower customer satisfaction. With regard to the efficiency and quality of public services is due in the halls of government, the administration building, public's satisfaction and retain customers with quality action. 


\section{References}

[1] Ghasemi, S.Z., Forghani Ozrudi, M.B. Investigate role of mediating quality of service to the relation between aesthetic and customer satisfaction in sport facilities in Mazandaran province. Journal of New World Quarterly, 2021; 4(14): 45-58.

[2] Geidne, S., Quennerstedt, M. \& Eriksson, C. The youth sports club as a health-promoting setting - An integrative review of research. Scandinavian Journal of Public Health, in press, 2013

[3] Jgibson, F., Lloyd, J., Bain, S. Hottel Derek: green design and sustainability in sport and recreation facility. Smart journal, 2008; 4(2): 26-33.

[4] Koshesh, K., Jalali Farahani, M., Alidost Ghahfarokhi, E. Relationship between fantasy view of sport facility and customer satisfaction. Bhu.J.RNR, 2015; 3(1): 353-358.

[5] Treid, M., Kenny, J. Training and development HDI, training intervention. Institute of personal management, London, 1996.

[6] Nopembri, S. The development of sport facilities management to support sport tourism, Yogyakarta State University, 2009.

[7] Jalali Farahani, M. Management of leisure and recreational sports. Tehran University Press, 2014.

[8] Mohammadi Seresht, M. Analysis and review of concepts of sustainability in the architectural design of sports complexes of the third millennium, the Second International Conference on New Horizons in Engineering Sciences, Istanbul, Turkey, 2018.

[9] Stklair, L. Iconic architecture and culture ideology of consumerism. Theory culture \& society, 2010; 27(5): 135-159.

[10] Heddersen, A., Maennig, W. Arenas versus multifunctional stadiums: which do spectators prefer? Journal of sport economics, 2009; 10: 180-191.

[11] Elahi, A., Pouraghaei Ardekani, Z. Check the status of football stadium compared with European standards. Journal of motion, 2005; 19: 79-63.

[12] Jalali Farahani, M. Facilities management facilities and fitness equipment. Tehran University Press, 2022.

[13] The five-year program of physical education departments in the country (2005). Vice president of strategic planning and management of the National Center for Sports development. tehran.

[14] Khabiri, M. Comparison of selected clubs from Japan, South Korea, UAE, and Turkey. Research projects Institute of Physical Education and Sports Science. Research in sports science, 1995; 3(8): 15-34.

[15] Amini, M., Amini, M., Mahdipour, A., Ghasemi, H. Explanation and evaluation indexes Effectiveness industry barriers of Sports tourism with group AHP method Emphasizing the role of information and communication. Communication Management in Sport Media, 2017; 4(3): 27-36.

[16] Daliri, F. Side view of the city. Congress engineers and city planners و2013.

[17] Haghgoo, F., Mulla Salehi, V. Recognition of criteria of identity and aesthetics as components of the effect on the design of facades and walls of Tehran (study area of the fourteenth district of Tehran). Architecture, 2021; 3(16), 1-11.

[18] Liu, Y.C., Chen, T.L. An Analysis of Service Quality, Customer Satisfaction and Customer Loyalty of Commercial Swim Clubs in Taiwan. 弘光人文社會學報, 2012; 1(15): 133-154.

[19] Qasemzadeh Mirkalai, I., Amirnejad, S., Razavi, S.G. Assessing the level of customer satisfaction with the quality of services provided in private and public indoor pools. Journal of North Sports Management and Physiology, 2014; 1(1), 58-44.

[20] Bahlakeh, T., Hamidi, M., Goudarzi, M. Factors related to customer satisfaction, private pools covered in Tehran, Journal of Harkat, 2009; 37, 49-58.

[21] Goharrostami, H. Customer satisfaction survey of public and private fitness clubs for men in Tehran and ranking factors, the National Congress of Sport Management abstracts focusing on visions of 20-year-old Islamic Republic of Iran, Bamdad Ketab Pub, 2009; p; 131.

[22] Hamzehpour, M. The relationship between service quality, customer satisfaction and loyalty with fitness clubs in Mazandaran province, Apr MA thesis, Shomal University, 2012.

[23] Amirnezhad, S., Hamzepour, M., Yamini, M. Evaluation of satisfaction of services from the perspective of student's wrestler wrestling clubs in Mazandaran (case study: the city of Babol, the first National Conference on Physical Education and Sports Science Applied Science student Shahid Beheshti University in Tehran, 2013.

[24] Hasibi, S., Forghani, M.B., Kafi Zare, M., Ghafarian Panahi, A. Study of Aesthetic and Service Quality in the Sport Pools and Its Relation with Customer Loyalty with an Emphasis on Customer Incentives. Journal of Applied Science and Agriculture, 2014; 9(4), 1992-1999.

[25] Forghani Ozrudi, M., Masomi Shob, M., Sadeghi, M. Relationship between Service Quality and Aesthetic Dimensions with Customer's loyalty. Sport Management Studies, 2016; 7(34), 91-112. 